\title{
Porosity variation of lithium-ion battery separators under uniaxial tension
}

DOI:

10.1016/j.jijmecsci.2020.105496

\section{Document Version}

Accepted author manuscript

Link to publication record in Manchester Research Explorer

\section{Citation for published version (APA):}

Wang, Y., Li, Q., \& Xing, Y. (2020). Porosity variation of lithium-ion battery separators under uniaxial tension. International Journal of Mechanical Sciences, 174, [105496]. https://doi.org/10.1016/j.ijmecsci.2020.105496

\section{Published in:}

International Journal of Mechanical Sciences

\section{Citing this paper}

Please note that where the full-text provided on Manchester Research Explorer is the Author Accepted Manuscript or Proof version this may differ from the final Published version. If citing, it is advised that you check and use the publisher's definitive version.

\section{General rights}

Copyright and moral rights for the publications made accessible in the Research Explorer are retained by the authors and/or other copyright owners and it is a condition of accessing publications that users recognise and abide by the legal requirements associated with these rights.

\section{Takedown policy}

If you believe that this document breaches copyright please refer to the University of Manchester's Takedown Procedures [http://man.ac.uk/04Y6Bo] or contact uml.scholarlycommunications@manchester.ac.uk providing relevant details, so we can investigate your claim.

\section{OPEN ACCESS}




\title{
Porosity variation of lithium-ion battery separators under uniaxial tension
}

\author{
Yu Wang ${ }^{\text {a }}$ Q. M. Li ${ }^{\text {a, }}$, Yuyang Xing ${ }^{\mathrm{a}}$ \\ ${ }^{a}$ Department of Mechanical, Aerospace and Civil Engineering, School of Engineering, The University of \\ Manchester, Manchester M13 9PL, UK
}

\begin{abstract}
Separators in lithium-ion batteries are susceptible to uneven distributions of deformation, which may lead to inhomogeneous porosity distribution when batteries are subject to complex external loadings. In this study, uniaxial tensile tests were performed for four types of commercial separators and the in-situ 3D Digital Image Correlation (DIC) technique was used to measure the strain fields. In order to minimise the adverse effect caused by the wrinkling in strip-shaped specimens, dogbone-shaped specimens were designed to improve the measurement consistency by avoiding the occurrences of wrinkles in wet-processed separators whose deformation response has weak anisotropy. Homogeneous strain distributions were observed in both wet- and dry-processed separators oriented in the machine direction, but two deformation mechanisms of necking were found for dry-processed separators in the transverse direction. In the range of strain between 0 and 0.5 , no thickness change was found in all separators, and large in-plane Poisson's ratio (up to 1.4) was found in wet-processed separators. The relationship between longitudinal and transverse strains was determined experimentally, based on which the in-plane Poisson's ratio is expressed as a polynomial function of longitudinal strain. Finally, relationship between material porosity and longitudinal strain were determined which can provide additional information in multiphysics simulations.
\end{abstract}

Keywords: Lithium-ion battery; Separator; Digital image correlation; Poisson's ratio; Porosity; Mechanical abuse

\footnotetext{
${ }^{*}$ Corresponding author.

E-mail address: qingming.li@manchester.ac.uk (Q.M. Li).
} 


\section{Introduction}

Since Sony invented and launched its first commercial lithium-ion batteries (LIBs), this high energy secondary battery technology has been developed for over 20 years. Today, LIBs have been used widely as power sources for many applications (e.g. mobiles, grid energy storage, Electric Vehicles (EVs)) due to its advantages such as high energy density, low maintenance and variety of available types and shapes. Typically, a single LIB consists of three functional parts of cathode, anode and separator. Separator is a permeable membrane placed between anode and cathode to prevent the short circuit, meanwhile allowing the transport of ionic charge carriers $[1,2]$. Separator is the most important part for the safety of LIBs, and therefore, its mechanical properties and pore characterisation have received great attentions from researchers [3].

The mechanical properties of separators have been comprehensively investigated and their constitutive models [4-10] depend on manufacturing process, environmental conditions (e.g. wet/dry [5-7], temperatures [8], charge-discharge cycles [9] and strain-rates $[5,7,8,10])$. Engineering strains were either measured from the crosshead displacements $[5,7,11,12]$ or using digital image correlation (DIC) method [8, 10, 13-16]. DIC is a technique to measure the full-field displacement and strain by correlating the images of a tested specimen at different incremental deformation steps, which can produces high resolution deformation field on its surface [17]. As a non-destructive testing (NDT) method, DIC can avoid the errors caused by slipping and uneven deformation near the mechanical grips and provide more accurate measurements, which is particular useful for the material tests of thin-film specimens at macroscopic level [18]. However, most of the uniaxial tensile tests of separators used DIC in 2D mode via a single camera $[8,10,13,14,18]$, which may cause measurement errors if the camera is not perfectly perpendicular to the sample surface [19] or the sample has small out-of-plane displacements [20]. In addition, the selection of the virtual strain gauge (VSG) length area may influence the DIC measurement [21] due to the non-uniform strain distribution in the VSG length area [10]. Moreover, strip-shaped samples were used in most studies according to ASTM D882, which, however, may sometimes cause wrinkling and non-uniaxial tension stress state during a test [13, 22, 23]. To overcome the weakness of the strip-shaped sample, a dogbone-shaped specimen is designed in this study based on this standard to investigate whether it can improve the accuracy of the experiment. 
Although Poisson's ratio is an important mechanical property for separator materials, there are limited publications on their experimental measurements. As the only publication based on authors' best knowledge, Yan et al. [18] found that the in-plane Poisson's ratio of monolayer polypropylene (PP) separators varies with strain, and it only obeys the elastic symmetry relationship of an orthotropic material in a very small range of strain (up to 0.01 in [18]). In constitutive models for separators, Poisson's ratio values are usually set between 0.3 and $0.5[4,24]$.

The porosity of a separator is equally important to understand its mechanical behaviours. Excessive porosity can increase the ionic conductivity [25] but will adversely influence the overheat shutdown performance [2], which is important for the safety of LIBs. The nonuniform porosity distribution will also lead to an uneven distribution of the electric current, resulting in the lithium plating and lithium dendrites [26-29]. In most previous studies, the porosity of the separators was regarded as a constant value with uniform distribution. However, it has been shown that non-uniform stress and strain distributions can be generated in LIBs under complex external loading conditions [30-33], leading to non-uniform and varying porosity in separators [34, 35], which may affect separator's electrochemical properties (e.g. tortuosity, resistance, etc.) [36] and other physical properties (e.g. permeability) at both microscopic [34] and macroscopic levels [35]. Therefore, it is necessary to understand the relationship between porosity and strain state in a separator.

In this study, uniaxial tensile tests were performed on four types of commercial separators, i.e. two typical dry-processed Celgard separators and the wet-processed Asahi Hipore separators with two different thickness values. Two specimen geometries were used to obtain full-field strains using 3D DIC measurement technique, in which different sizes of VSG were examined. In addition, the variation of the macroscopic Poisson's ratio caused by the change of pore structure is studied, and the relationship between the porosity and the tensile strain of the separators is determined. Finally, a model to describe the relationship between separator's Poisson's ratio and porosity is proposed, which can be used in analytical and numerical models. 


\section{Materials and methods}

\subsection{Materials}

Commercial separators of monolayer polythene (PE) Asahi Kasei Hipore, monolayer PP Celgard 2500 and tri-layer (PP/PE/PP) Celgard 2325 were selected in this study with considering their wide usage [29] and different manufacturing methods. The Asahi Kasei Hipore samples are made by the wet-process with two thicknesses of $16 \mu \mathrm{m}$ and $25 \mu \mathrm{m}$, and thus, Hipore-16 and Hipore-25 were used to represent them, respectively. The Celgard samples are all made by the dry-process method with a thickness of $25 \mu \mathrm{m}$. In order to find out the geometry of the thin film specimens that can give reliable results, both dogboneshaped and strip-shaped specimens were used in this study. Based on previous studies, the rectangular thin film with the length-to-width aspect ratio greater than 3.7 can give uniaxial stress state in a uniaxial tensile test [37], and meanwhile meet the requirement of ASTM D882 standard. The specific cutting tool and the schematic of dogbone-shaped samples are shown in Figs. 1(a) and 1(b). Strip-shaped specimens were cut into $80 \mathrm{~mm}$ in length and 8mm in width by Swann Morton No 10A Surgical Scalpel Blade, and the grip separation was set to be $40 \mathrm{~mm}$, as shown in Fig. 1(c). To minimise the influences of the edge cutting and the localised compressive stress state near the clamped ends, the area of $25 \mathrm{~mm} \times 6 \mathrm{~mm}$ in the centre is defined as the gauge area here. The printing paper was attached to the grip areas of specimens by super glue to prevent the specimens from tearing and slipping between the grips.

The microstructures of undeformed and deformed samples were taken using a Scanning Electron Microscope (Zeiss Sigma VP FEG SEM). A $10 \mathrm{~nm}$ thick layer of platinum was sputtered on the samples to avoid the charge build-up in SEM. Since it is difficult to carry out the in-situ tensile tests on separators (the electric beam can damage the new fibrils created without coating) [38], the deformed samples were imaged 4 days after the tensile test. It is noted that, after the samples were fully unloaded, they still experienced a slight recovery within 48 hours due to material's viscoelasticity, after which no further recovery can be found. 


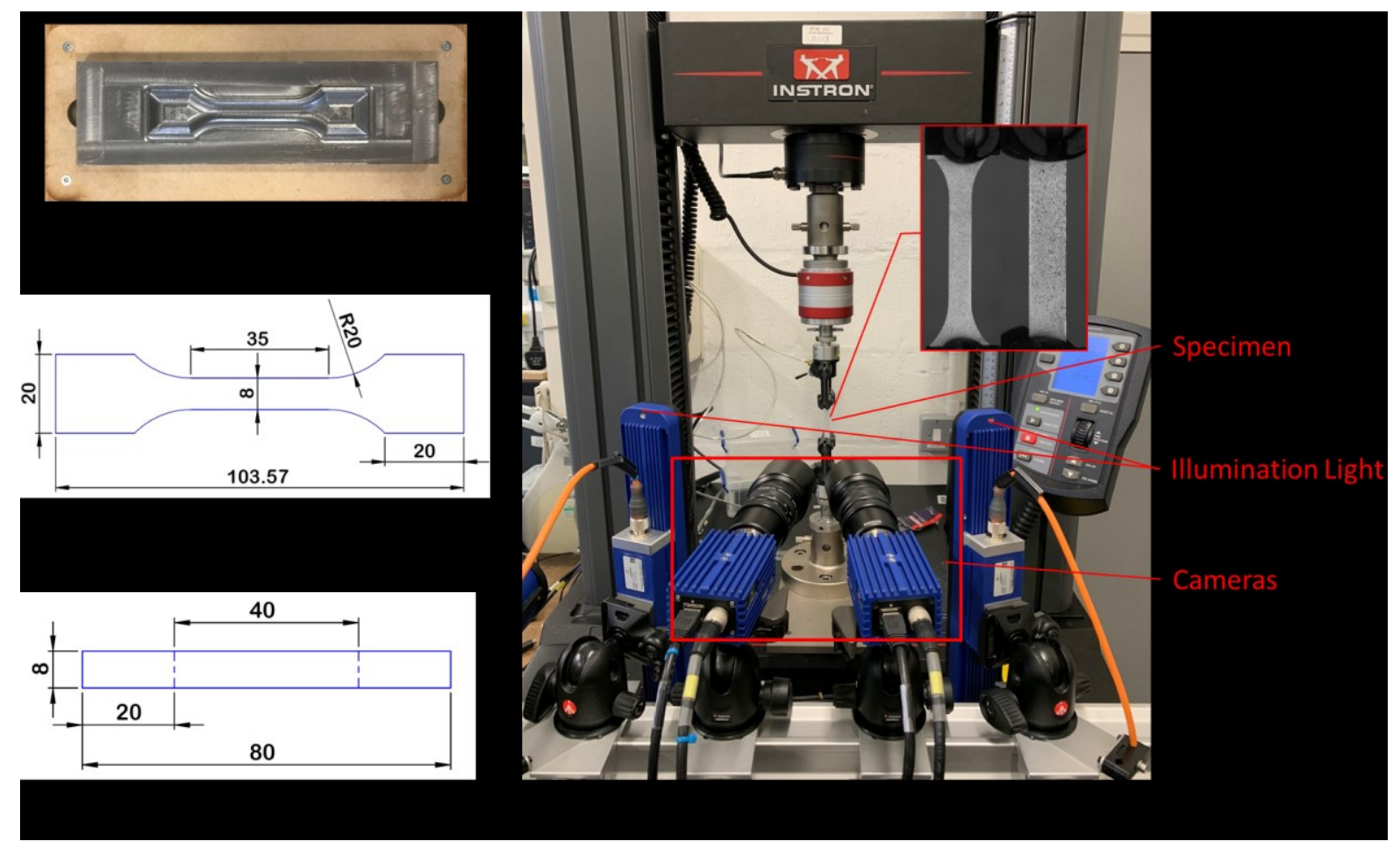

Fig. 1 (a) The dogbone cutting tool; (b) dogbone-shaped sample; (c) strip-shaped sample; (d) the DIC setup with patterned sample mounted on the pneumatic grips.

\subsection{Loading and strain measurement}

The strip-shaped specimens and dogbone-shaped specimens were mounted in the pneumatic grips according to ASTM D882 and loaded by an Instron loading frame with a $1000 \mathrm{~N}$ load cell. All experiments were conducted at room temperature in the ambient atmosphere with three repeats for both machine direction (MD) and transverse direction (TD) at a quasi-static strain-rate of $10^{-3} \mathrm{~s}^{-1}$. In order to obtain accurate results from DIC, all tests were stopped when the sample was damaged or the number of recording images reached 1000.

The longitudinal and transverse strains of the specimens during testing were measured by the 3D DIC technique. To track the deformation during the test using DIC technique, random speckle patterns on the specimens were created by spraying black paint on specimen surfaces (images of the amplified specimens in the red box in Fig. 1(d)) using a $0.35 \mathrm{~mm}$ nozzle airbrush. The pattern motion on the surface of the specimen caused by the applied load can be tracked and correlated to the reference image, and therefore, the displacements and the strains can be calculated. 
The DIC system manufactured by LaVision was set up as shown in Fig. 1(d). Unlike 2D DIC, stereo calibration was required using a small etched calibration grid before carrying out the 3D DIC experiment. The image was taken every second and the analogue outputs of load and displacement were used to synchronise the DIC and Instron loading machine. The calibration and image data were recorded by DaVis software via two Imager E-lite 5M CCD cameras (resolution of 2456 pixel $\times 2058$ pixel) and the experimental results were processed and computed by StrainMaster software. For each experiment, six different size VSGs, ranging from $25 \mathrm{~mm} \times 6 \mathrm{~mm}$ down to $1 \mathrm{~mm} \times 2 \mathrm{~mm}$, were applied in DIC analysis to explore the effects of the VSG size. The DIC resolution uncertainty was estimated to be $0.005 \%$ strain based on the strain calculations from two recorded images of the sample in still position under the same setting.

\subsection{Initial porosity measurement}

Porosity is defined as the ratio of the void volume to the total volume that includes the void volume and the matrix material volume of the separator. Electrolyte uptake method [39], mercury intrusion porosimetry (MIP) [1], gas pycnometry [40, 41], scanning electron microscope (SEM) [34] and X-ray computed tomography [42] were commonly used to determine the porosity of the samples. Material densities and porosities of the Celgard separators can be obtained from available data [42, 43], while material densities and the porosities of the Hipore separators were measured by the non-destructive gas (i.e. helium was used in this study) pycnometry technique using AccuPyc II 1340. The porosities of all samples were summarised and listed in Table 1. It is interesting to notice that the porosities in try-layer separator samples are different in PP and PE layers since lower porosity PP layers are designed to have better mechanical integrity and PE layer with lower melting temperature is designed to shut down the transport pathway of ionic charge carriers when thermal runaway occurs.

Table 1

Characterisations of separator samples.

\begin{tabular}{lllll}
\hline Sample & Composition & \multicolumn{2}{l}{ Density $\left(\mathrm{g} \mathrm{cm}^{-3}\right)$} & Initial porosity \\
& & Avg & Stdev & \\
\hline Celgard 2325 & PP/PE/PP & $0.91[43]$ & - & $41 \%$ (39\% for PP layers, 44\% for PE layer) [42] \\
Celgard 2500 & PP & $0.91[43]$ & - & $53 \%[42]$ \\
Hipore-16 & PE & 0.9927 & 0.0023 & $41.84 \%$ \\
Hipore-25 & PE & 0.9748 & 0.0013 & $40.79 \%$ \\
\hline
\end{tabular}




\section{Relationship between porosity and strain under uniaxial tension}

It has been shown that the Poisson's ratios of the polymer matrix of the separator is relatively high (e.g. 0.42 in [44]), which approaches to the Poisson's ratio value of 0.5 for incompressible isotropic materials. Therefore, the solid volume of the separator materials may be considered approximately as a constant during the test [35] based on the principle of mass conservation. Hence, the relationship between the current porosity $\Phi$ and the corresponding longitudinal strain $\varepsilon_{l}$ of the deformed separator can be expressed as

$\Phi\left(\varepsilon_{l}\right)=1-\frac{V_{0}\left(1-\Phi_{0}\right)}{V\left(\varepsilon_{l}\right)}$

where $\Phi_{0}$ is the initial porosity, $V_{0}$ is the initial volume of the gauge area; $V\left(\varepsilon_{l}\right)$ is the current volume of the gauge area at longitudinal strain $\varepsilon_{l}$. The current volume can be calculated by multiplying the measured length, width and thickness before the occurrence of necking. The thicknesses of all samples were measured before and after test by a micrometre with $1 \mu \mathrm{m}$ accuracy according to [2]. Interestingly, apart from the necking area of tri-layer Celgard 2325 TD sample, no thickness variation was found in all samples, which means that the thickness can be regarded as a constant until the start of necking. The details of the measurement and phenomenon can be seen in Appendix A. The in-situ length and width measurements were converted from the strain measured via 3D DIC, and Eq. (1) can be rewritten as

$\Phi\left(\varepsilon_{l}\right)=1-\frac{l_{0} w_{0}\left(1-\Phi_{0}\right)}{l_{0}\left(1+\varepsilon_{l}\right) w_{0}\left(1+\varepsilon_{t}\right)}=1-\frac{1-\Phi_{0}}{\left(1+\varepsilon_{l}\right)\left(1+\varepsilon_{t}\right)}$

where $\varepsilon_{t}$ is the measured transverse strain, $l_{0}$ is the initial length and $w_{0}$ is the initial width of the gauge area. According to the definition of Poisson's ratio in the longitudinal direction, i.e. $v=-\varepsilon_{t} / \varepsilon_{l}$, the porosity can be finally expressed as

$\Phi\left(\varepsilon_{l}\right)=1-\frac{1-\Phi_{0}}{\left(1+\varepsilon_{l}\right)\left(1-v \varepsilon_{l}\right)}$

It should be noted that the Poisson's ratio could be a variable function of the longitudinal strain, i.e. $v=v\left(\varepsilon_{l}\right)$. 


\section{Results and discussion}

\subsection{DIC results}

The typical transverse strain vs. longitudinal strain curves are measured for all samples by applying a $25 \mathrm{~mm} \times 6 \mathrm{~mm}$ VSG in the gauge area, as shown in Fig. 2 where the error bars are determined by standard deviation. The uniaxial tensile engineering stress-strain curves for all samples are provided in Appendix A.

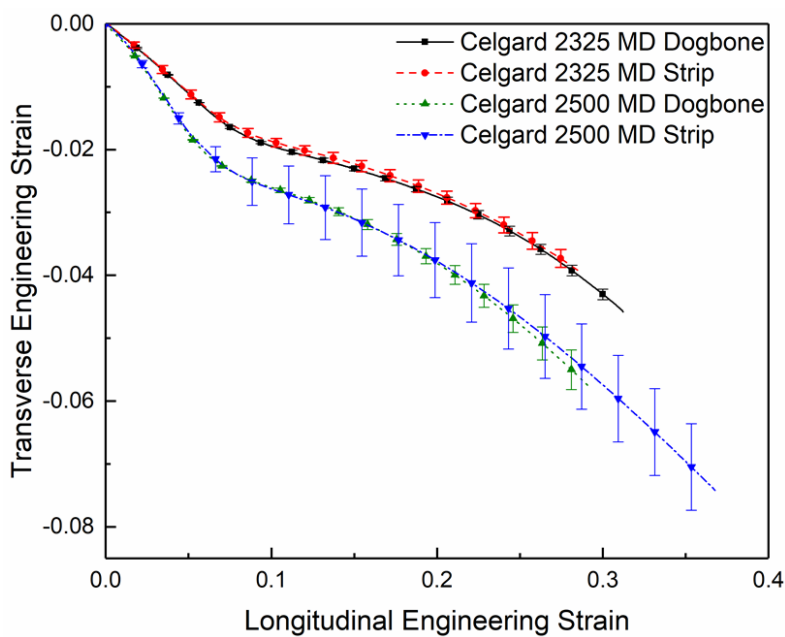

(a)

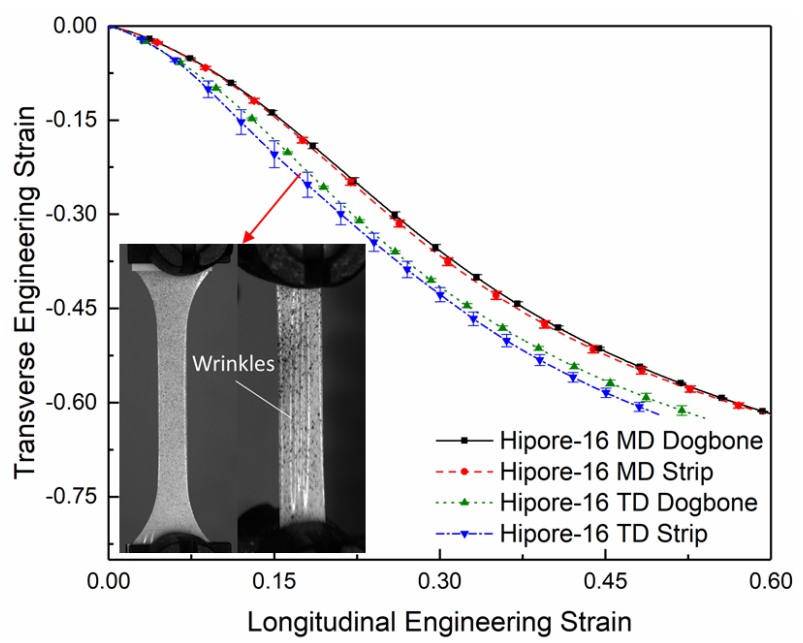

(c)

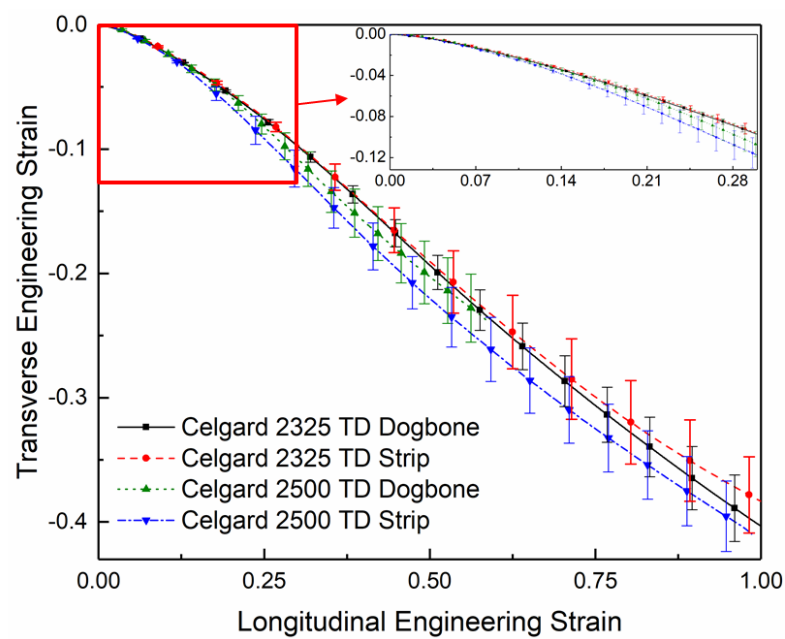

(b)

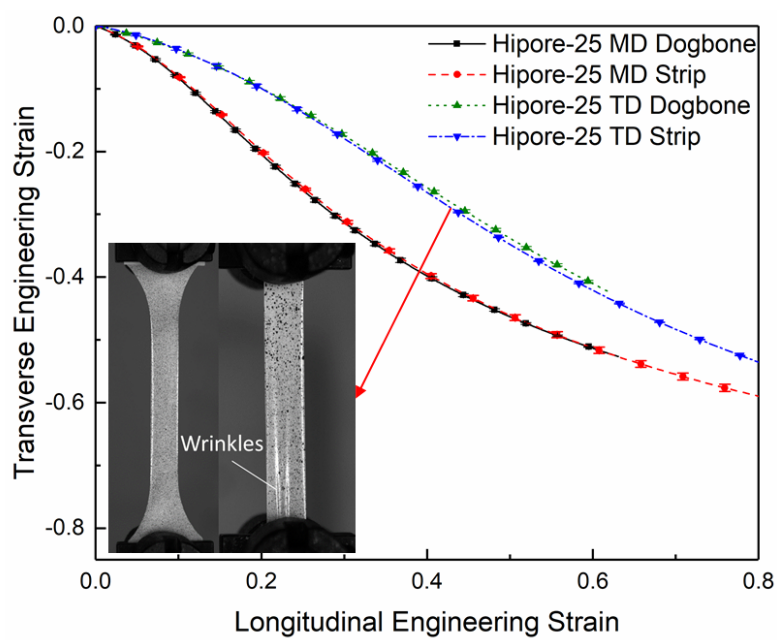

(d)

Fig. 2 The transverse vs. longitudinal strain curves of (a) Celgard separators in MD, (b) Celgard separators in TD, (c) Hipore-16 and (d) Hipore-25.

As shown in Fig. 2, the dogbone samples generally have better repeatability than the strip ones. However, it is noted that the results of the longitudinal strain vs. transverse strain curves for dry-processed Celgard in TD have relatively large standard deviations since the 
speckle patterns hidden in the wrinkle areas are not tracked effectively. According to previous study, the stretch-induced wrinkles are inevitable when a high anisotropic thin film is stretched in the low-stiffness direction [22], and this phenomenon can be observed in both dogbone and strip shapes of Celgard samples here.

For the wet-processed Hipore separators, although their TD stiffness is similar to their MD stiffness, the same wrinkling phenomenon is observed in strip samples, but no wrinkle has been found in dogbone samples, as shown in Figs. 2(c) and 2(d). In strip samples, the lateral contractions of the film caused by Poisson's effect are prevented by the clamped boundaries at two grip ends, which generate transverse compressive stress in the central area near the grips [37] and the thin film buckles to accommodate the in-plane strain incompatibility [45]. For the dogbone samples, the transverse compressive stress and the resulting buckles are localised in the wider areas near the grips, which do not extend to the gauge area. Even though the transverse compressive stress is negligible compared to the tensile stress, the produced wrinkles affect adversely the DIC results.

To investigate the influence of VSG size and the strain distribution on the samples, a parametric study of VSG and the full-field strain observation have been carried out. Fig. 3 presents the typical longitudinal strain vs. transverse strain curves obtained using different VSG sizes. The VSGs are applied to the centre of the gauge area for the specimens without apparent necking. For the specimens with noticeable necking, in order to find out the difference of the longitudinal strain vs. transverse strain relationships between the necking and other areas, the VSGs with the length of $1 \mathrm{~mm}$ are applied to the necking area while there is no change of the other VSG sizes in other areas. The longitudinal strain vs. transverse strain curves for other samples are provided in Appendix A, which show high consistence and similar feature as Celgard $2325 \mathrm{MD}$.

As shown in Fig. 3, apart from the Celgard 2325 separators in TD, the results of other samples indicate that the relationships between longitudinal strain vs. transverse strain are almost independent of the VSG size, which means that Poisson's ratios of these samples can be determined reliably using the VSG sizes examined. 

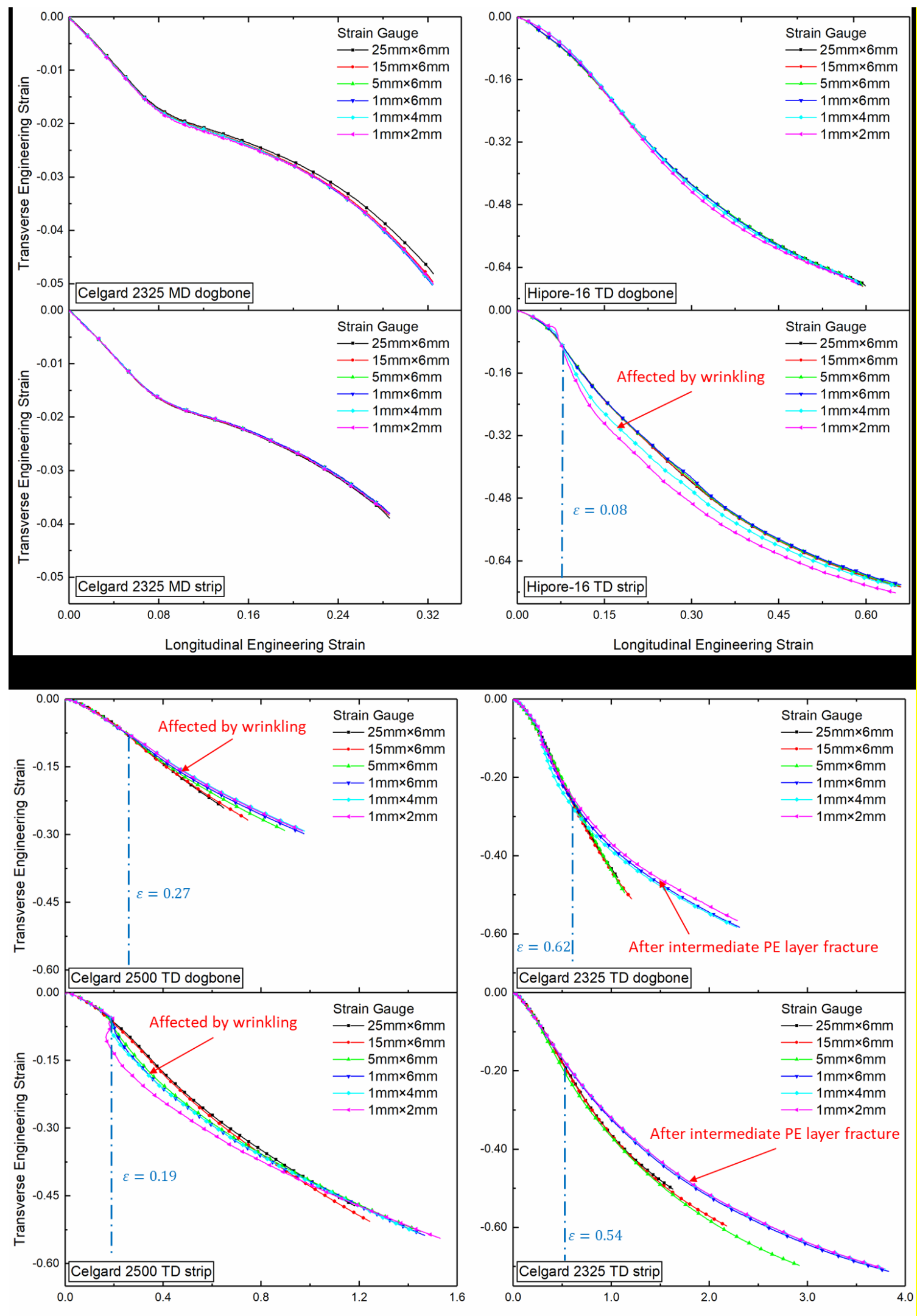

Longitudinal Engineering Strain

Longitudinal Engineering Strain

Fig. 3 The transverse strain vs. longitudinal strain curves with different VSG for (a) Celgard 2325 MD, (b) Hipore-16 TD, (c) Celgard 2500 TD, and (d) Celgard 2325 TD. 
For the samples without necking, uniform distribution of both axial and transverse strains can be observed from Figs. 4(a) and 4(b), and Figs. A2 and A3 in Appendix A, which remains until failure or the end of tests, except the poor results caused by wrinkles in stripshaped Hipore-16 TD (Fig. 4(b)). The wrinkles cause measurement errors and result in the inconsistence of the curves starting from longitudinal strain of 0.08, as shown in Fig. 3(b).

For the samples with necking appearance, two different deformation mechanisms can be observed. For the Celgard 2500 in TD, even though the high localised strains generated in the necking area (Fig. 4(c)) may cause the non-uniform distributions of longitudinal strain, it is observed from Fig. 3(c) that the relationships between transverse and longitudinal strains are insensitive to the selection of the VSG size. However, similar to strip shaped Hipore-16 TD (Fig. 3(b)), inconsistent transverse strain vs. longitudinal strain curves caused by wrinkling are also observed after longitudinal strains of dog-bone shaped sample and strip shaped sample reach 0.27 and 0.19 , respectively. For the Celgard 2325 in TD, even though a similar necking phenomenon is found, Fig. 4(d) shows that the local necking strains can reach a higher value over $300 \%$ (this phenomenon has been also observed by Kalnaus et al. [10]). In addition, curves of the relationship between the transverse and longitudinal strains start to be divided into two paths when the longitudinal strain reaches 0.62 in dogbone-shaped sample and 0.54 in strip-shaped sample, as shown in Fig. 3(d), which is different from the phenomenon in strip-shaped Hipore-16 TD and Celgard 2500 TD. The curves for small VSGs with length of $1 \mathrm{~mm}$ applied on the necking regions become consistent and converge to one path, while the curves for other VSGs converge to another path. According to the SEM images of the necking cross-section area of the tri-layer Celgard 2325 separator before test [1] and after test (as shown in Figs. 4(e) and 4(f), respectively), together with the observation of the 1/3 thickness reduction of the necking region (see in Appendix A1), it suggests that the intermediate PE layer is fractured after the start of inconsistence. Therefore, the transverse strain vs. longitudinal strain curves, obtained from small VSG length after the occurrence of inconsistence, are the curves of the separator with only two PP layers instead of the original tri-layer one. 


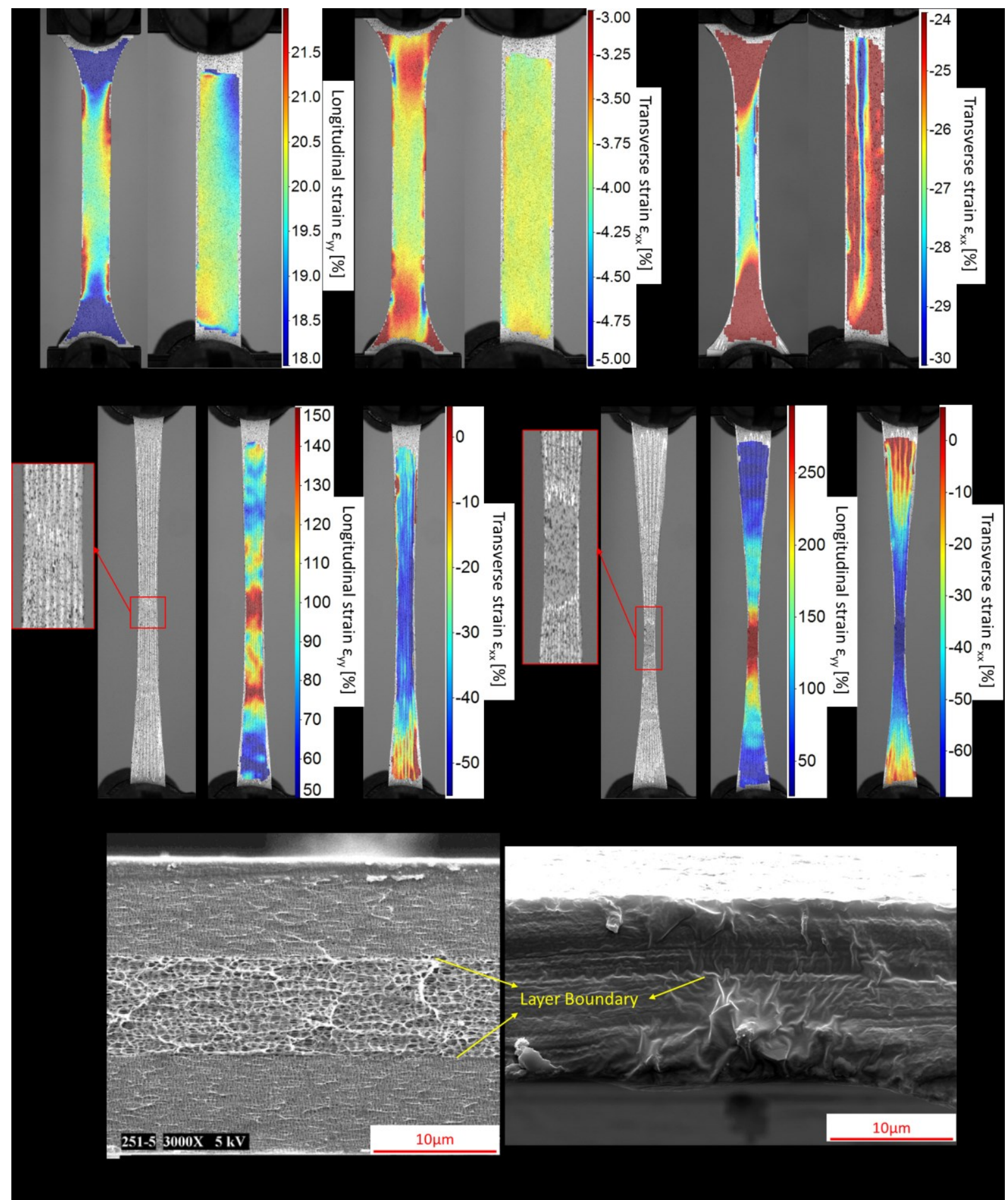

Fig. 4 Strain distributions of (a) Celgard 2325 MD, (b) Hipore-16 TD at longitudinal strain of 0.2; the original images and the strain distributions in (c) Celgard $2500 \mathrm{TD}$, and (d) Celgard $2325 \mathrm{TD}$ at the grip movement of 36mm; the SEM images of the necking cross-section areas of Celgard 2325 before tests [1] (e), and after tests (f).

The underpinning causes for the influence of VSG size and the characteristics of the curves are summarised in Table 2. 
Table 2

Summary of the influence of VSG size and the underpinning causes.

\begin{tabular}{|c|c|c|c|c|}
\hline Sample & & & Features of varying VSG curves & Causes \\
\hline \multirow[t]{4}{*}{ Celgard 2325} & MD & Dogbone & Consistent & - \\
\hline & & Strip & Consistent & - \\
\hline & TD & Dogbone & $\begin{array}{l}\text { Curves for small VSG lengths converge to } \\
\text { another path after longitudinal strain of } 0.62 \text {. }\end{array}$ & Middle PE layer rupture \\
\hline & & Strip & $\begin{array}{l}\text { Curves for small VSG lengths converge to } \\
\text { another path after longitudinal strain of } 0.54 \text {. }\end{array}$ & Middle PE layer rupture \\
\hline \multirow[t]{4}{*}{ Celgard 2500} & MD & Dogbone & Consistent & - \\
\hline & & Strip & Consistent & - \\
\hline & TD & Dogbone & $\begin{array}{l}\text { Curves for small VSG lengths do not } \\
\text { converge after longitudinal strain of } 0.27 \text {. }\end{array}$ & Wrinkling \\
\hline & & Strip & $\begin{array}{l}\text { Curves for small VSG lengths do not } \\
\text { converge after longitudinal strain of } 0.19 \text {. }\end{array}$ & Wrinkling \\
\hline \multirow[t]{4}{*}{ Hipore-16 } & MD & Dogbone & Consistent & - \\
\hline & & Strip & Consistent & - \\
\hline & TD & Dogbone & Consistent & - \\
\hline & & Strip & $\begin{array}{l}\text { Curves for small VSG lengths do not } \\
\text { converge after longitudinal strain of } 0.08 \text {. }\end{array}$ & Wrinkling \\
\hline \multirow[t]{4}{*}{ Hipore-25 } & MD & Dogbone & Consistent & - \\
\hline & & Strip & Consistent & - \\
\hline & TD & Dogbone & Consistent & - \\
\hline & & Strip & Consistent & - \\
\hline
\end{tabular}

Based on the experimental results discussed in this section, video extensometer, instead of DIC, is recommended for the uniaxial tensile test of the samples with uniform strain distributions, which can monitor the strain results synchronously and save the post-processing time. DIC has great advantage for the analysis of complex and non-uniform strain distributions in the sample.

\subsection{Poisson's ratio}

It should be noted that, due to the high porosity and microstructural characterisation of the samples, the Poisson's ratio calculated based on the transverse and longitudinal strains is actually a macroscopic value, instead of an intrinsic material property. In this section, the variations of Poisson's ratio are studied for strains between 0 and 0.5 . The out-of-plane (i.e. through-thickness) Poisson's ratio is taken as 0 because no thickness change is found in this 
range of strain, which has been discussed in Section 4.1. However, it seems that the in-plane Poisson's ratio is related to the complex meso-scale interactions of the pore structures, and therefore, a polynomial equation of the longitudinal strain with higher orders is selected, i.e.

$v\left(\varepsilon_{l}\right)=\sum_{i=0}^{5} J_{i}\left(\varepsilon_{l}\right)^{i}$

where $\varepsilon_{l}$ is the longitudinal strain in the uniaxial stress state, and $J_{i}$ are deformation constants obtained by fitting the experimental results. Poisson's ratio vs. strain curves are shown in Figs. 5(a) and 5(b), and as a comparison, the transverse strain vs. longitudinal strain curves are also presented (Figs. 5(c) and 5(d)). Constants $J_{i}$ are summarised and listed in Table 3. The data obtained from dogbone samples with $25 \mathrm{~mm} \times 6 \mathrm{~mm}$ VSG are used in this section. 

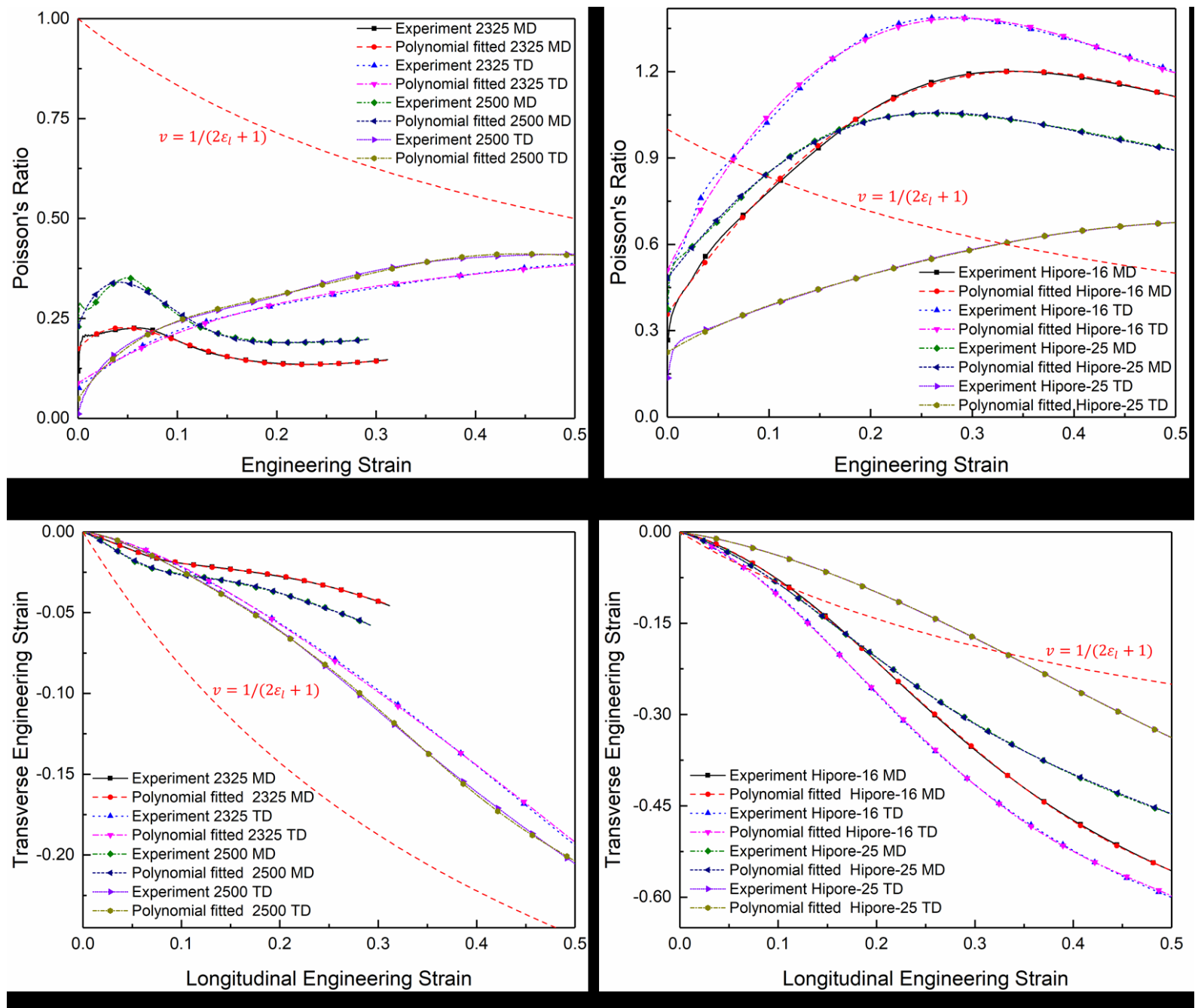

Fig. 5 The Poisson's ratio vs. longitudinal strain curves for (a) dry-processed Celgard separators, and (b) wet-processed Asahi Hipore separators; the transverse strain vs. longitudinal strain curves for (c) dry-processed Celgard separators, and (d) wet-processed Asahi Hipore separators. (Note: Red dashed curves represent Poisson's ratio for constant volume).

Table 3

Polynomial parameters in Eq. (4).

\begin{tabular}{llrrrrrl}
\hline Sample & Orientation & $J_{0}$ & $J_{1}$ & \multicolumn{1}{c}{$J_{2}$} & \multicolumn{1}{c}{$J_{3}$} & \multicolumn{1}{c}{$J_{4}$} & \multicolumn{1}{c}{$J_{5}$} \\
\hline Celgard 2325 & MD & 0.174 & 2.744 & -45.131 & 252.526 & -611.701 & 553.140 \\
& TD & 0.088 & 1.632 & -4.475 & 7.562 & -6.671 & 2.265 \\
Celgard 2500 & MD & 0.231 & 6.276 & -115.174 & 750.556 & -2135.757 & 2258.661 \\
& TD & 0.049 & 3.541 & -23.205 & 85.843 & -148.788 & 94.662 \\
Hipore-16 & MD & 0.357 & 5.124 & -7.655 & -2.596 & 6.040 & 1.729 \\
& TD & 0.510 & 7.006 & -17.730 & 18.002 & -21.024 & 21.735
\end{tabular}




\section{As the volume can be calculated by}

$V=t l w=t l_{0}\left(1+\varepsilon_{l}\right) w_{0}\left(1-v \varepsilon_{l}\right)$

where $t$ is the thickness, which is approximately a constant in this case. Hence, the change of the volume is

$d V=\left[1-\left(2 \varepsilon_{l}+1\right) v\right] V_{0}$

and the in-plane Poisson's ratio for the zero volume change (constant volume) can be obtained by

$$
v=\frac{1}{2 \varepsilon_{l}+1}
$$

which means the volume decreases under tension when the in-plane Poisson's ratio is greater than $1 /\left(2 \varepsilon_{l}+1\right)$, and volume increase when the in-plane Poisson's ratio is less than $1 /$ $\left(2 \varepsilon_{l}+1\right)$. In order to indicate the volume variations of the samples, the red dashed curves of $v=1 /\left(2 \varepsilon_{l}+1\right)$ are illustrated in Fig. 5 representing the constant volume. The experimental and polynomial fitted curves above the red dashed curves in Figs. 5(a,b) represent volume decrease under tension, while those below the red dashed curves represent volume increase under tension. Fig.5 (c,d) could be explained in a similar way.

It is shown that, for the dry-processed Celgard separators, the Poisson's ratios are fluctuated in MD and increased steadily in TD, but remain less than 0.4. However, for the wet-processed Asahi Hipore separators, large Poisson's ratios can be observed (especially for the Hipore-16 TD, which can reach 1.4 at strain around 0.3), which means that the volume is decreased under tension. This unusual phenomenon can be attributed to the pore closure phenomenon under uniaxial stretching of the wet-processed separators, which will be discussed further in Section 4.3. When the pores collapse, the void volume reduces with the negligible changes of matrix material volume and leads to the total volume decrease, which causes the occurrence of high Poisson's ratio. Therefore, even though the samples look like solid membranes, the invisible pore structures have strong influence on the transverse deformation and Poisson's ratio. 


\subsection{Porosity equation}

Based on Eq. (3) and Eq. (4), the variation of the porosity with longitudinal strain can be rewritten as:

$\Phi\left(\varepsilon_{l}\right)=1-\frac{1-\Phi_{0}}{\left(1+\varepsilon_{l}\right)\left(1-\varepsilon_{l} \sum_{i=0}^{5} J_{i}\left(\varepsilon_{l}\right)^{i}\right)}$

where initial porosity $\Phi_{0}$ and constants $J_{i}$ are given in Table 1 and Table 3, respectively. The porosity vs. strain curves for all samples are presented in Fig. 6.

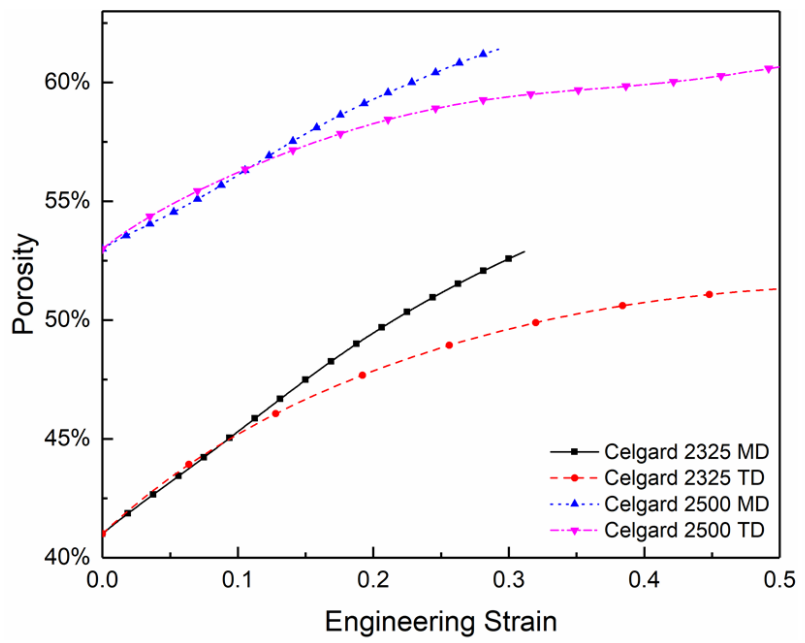

(a)

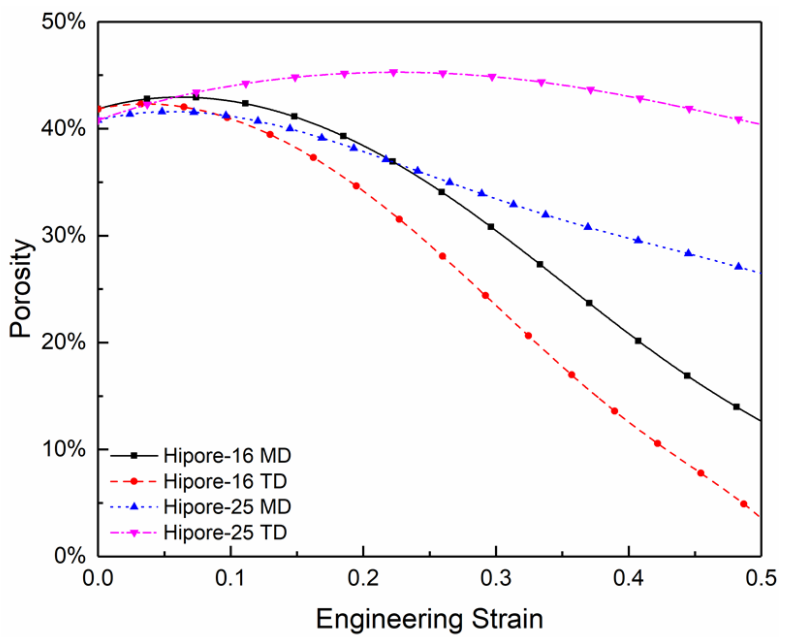

(b)

Fig. 6 The porosity vs. strain curves of (a) Celgard separators, and (b) Asahi Hipore separators.

It can be clearly seen that the porosities of the dry-processed Celgard separators increase steadily with the axial strains in both MD and TD. In the range of strain between 0 and 0.1 , the porosities of all Celgard samples increase linearly with strain by around $5 \%$. Then, the increase of porosity in MD is faster than that in TD. For the wet-processed Asahi Hipore separators, an opposite trend of porosity variation is observed compared to the dry-processed one. The porosities of all wet-processed samples increase slightly at the initial small strain, and then start to decrease with strain. Especially for the Hipore-16, the porosity is reduced significantly to less than $15 \%$ when the strain reaches 0.5 . The difference in porosity variation between dry-processed and wet-processed separators is due to the different pore structures from different manufacturing processes, as shown in Fig. 7. 


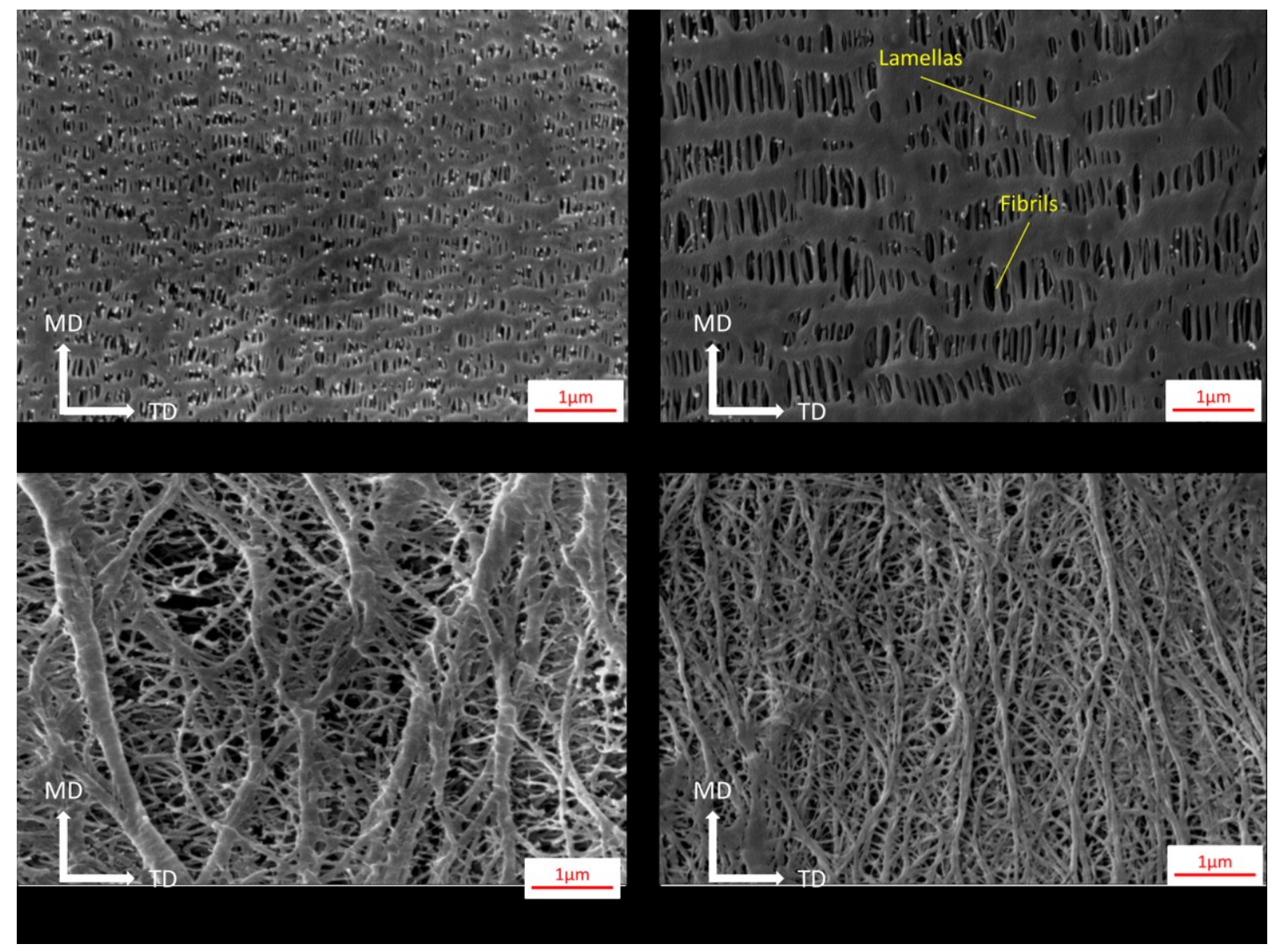

Fig. 7 SEM images of (a) Celgard 2325, (b) Celgard 2500, (c) Hipore-16 and (d) Hipore-25 before tensile test.

It can be clearly seen that the dry-processed separators have a split-like pore structure, which is mainly formed by the TD oriented lamellas and the MD oriented fibrils between lamellas (see Figs. 7(a) and 7(b)), while the wet-processed separators have pores formed by unoriented fibrils of different sizes (see Figs. 7(c) and 7(d)).

The phenomenon that the porosities of dry-processed separators increase with strains is supported by the interrupted in-situ tensile tests conducted by Zhu et al. [38]. When a dryprocessed separator is stretched in MD, the crazing of lamellas can cause the formation of new fibrils and new pores, and no change in pore size can be found. When it is loaded along $\mathrm{TD}$, no obvious new fibrils are developed, but the lamellas became thinner and the pore size is increased. Even the porous microstructures of a dry-processed separator are deformed in different ways when it is stretched in different directions, its porosities always increase as a result of increasing void volume with unchanged matrix material volume, which support the porosity equation (Eq.(5)) and the corresponding curves in Fig. 6(a). 
Fig. 8 illustrates the microstructures of the deformed wet-processed separators after four days from the tensile tests (i.e. after the full recovery of the viscoelastic deformation). Although they are not the instantaneous microstructures of the sample at the end of the tensile test, the variation trends of their pore structures have no fundamental differences from the predicted results in Fig.6(b). When the Hipore-16 is stretched, the fibrils are forced to form lamellas caused by transverse shrinkage, as shown in Figs. 8(a) and 8(b). Significant poreclosure can be found in this $16 \mu \mathrm{m}$ thick wet-processed separator sample, especially for the one stretched in TD, which have a good agreement with the results in Fig. 6(b). Compared to Hipore-16, Figs. 8(c) and 8(d) show that Hipore-25 has a minor pore-closure characterisation under tensile loading. When Hipore-25 is stretched in MD, most of the pores are getting smaller and several bundles of thin lamellas are formed by the combination of fibrils, which is similar to the Hipore-16 stretched in MD. For the Hipore-25 stretched in TD, the pores are reshaped as a result of fibrils deformation, but no significant pore-closure can be found here, which also supports the trend shown in Fig. 6(b).

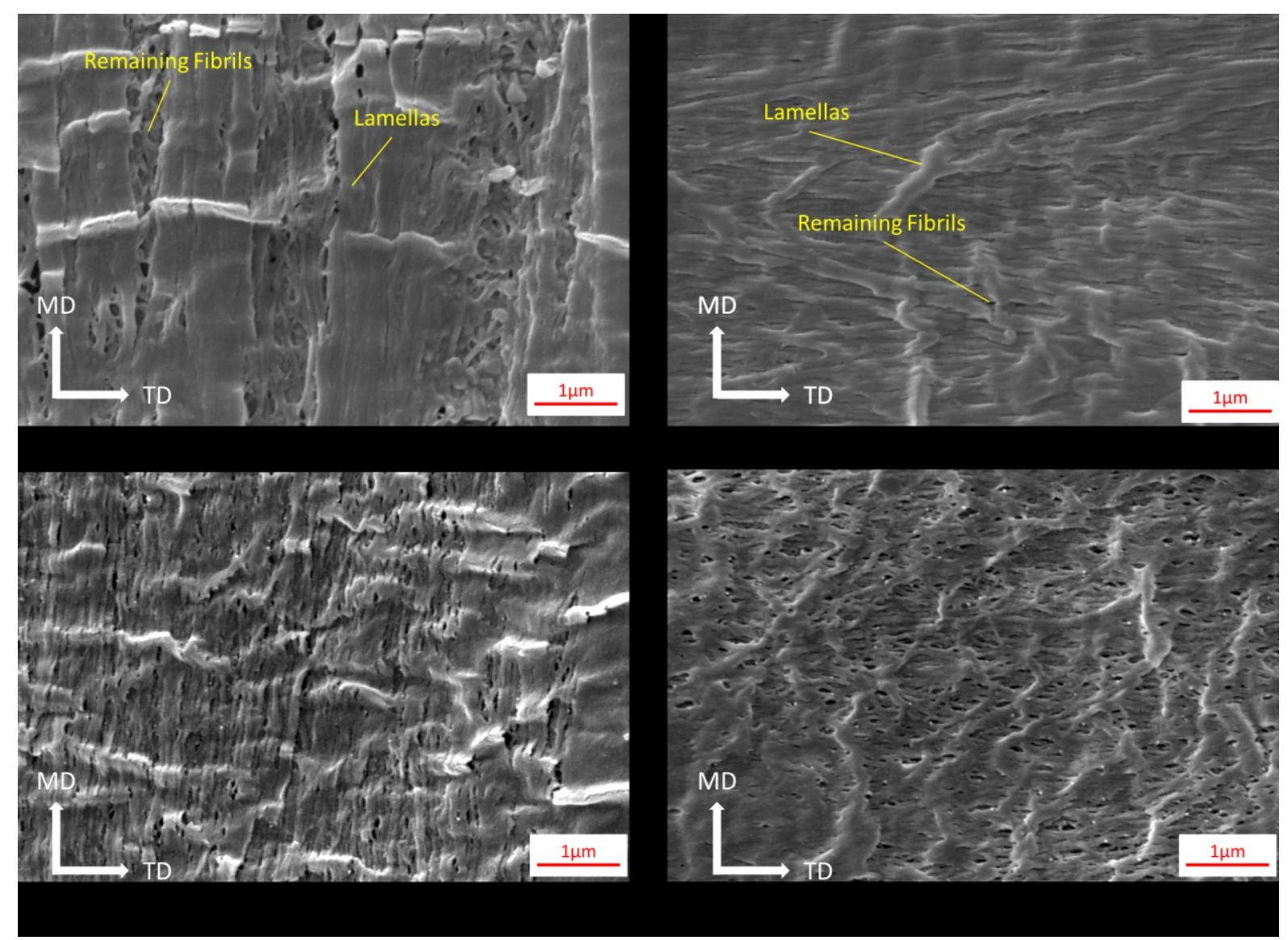

Fig. 8 SEM images of after deformed samples: (a) Hipore-16 MD, (b) Hipore-16 TD, (c) Hipore-25 MD and (d) Hipore-25 TD. 
Lastly, the mechanical safety of LIBs is an important issue for current industrial application such as EVs and other portable electronic products, and the separator is the most important factor to safety. Previously, studies of mechanical integrity were mostly focusing on the mechanical fracture of the separator on a macro-level when it suffered external loadings. However, when a LIB was deformed by an external loading (such as bending, crushing, etc.), deformations or strains were distributed inhomogeneously. The local uneven porosity of the separators caused by inhomogeneous strain distribution can result in nonuniform distribution of the electric current, which should be considered in multi-physics modelling.

\section{Conclusions}

In this study, mechanical behaviours and porosity variations of four typical types of commercial separators were investigated by uniaxial tensile tests monitored by $3 \mathrm{D}$ digital image correlation technique. It is found that dogbone-shaped samples had better consistent results by avoiding the appearance of wrinkling in the thin film compared to strip-shaped samples. Uniform strain distributions remain until the end of tests in both MD and TD of all wet-processed separators and in only MD of dry-processed separators while localised high strains and apparent necking are observed in TD of dry-processed separators. Three typical types of transverse strain vs. longitudinal strain curves for different virtual strain gauge (VSG) sizes are observed. For the samples without structure ruptures and wrinkling, high consistent curves are found in the measurements. For the samples with severe wrinkling but without structure rupture, curves for small VSGs do not converge after a certain longitudinal strain. For the Celgard $2325 \mathrm{TD}$, as the intermediate PE layer rupture occurs in the necking region, the curves for small VSGs applied on necking converge to a different path compare to the curves for other VSGs.

In the range of strain between 0 and 0.5 , the out-of-plane Poisson's ratio can be regarded as zero and no thickness change can be found, while the in-plane Poisson's ratio varies with strain for all separators due to the meso-scale interactions of the pore structures. A polynomial function is used to describe the relationship between Poisson's ratio and longitudinal strain, and the coefficients are fitted by the DIC results. Distinct variations of Poisson's ratios are found in different samples, i.e. relatively small variations of Poisson's ratio (remained below 0.4) are found in dry-processed separators, while Poisson's ratios of wet-processed separators increase considerably and even exceed unity for the one with 
thickness of $16 \mu \mathrm{m}$. The porosity variations associated with strains are calculated by the deformation based on the assumption of constant volume of the matrix material. Different relationships between porosity and strain are found, in which the porosities of dry-processed separators increase with strain while the porosities of wet-processed separators decrease with strain. These characterisations also have a good agreement with the previous work [38] and SEM images of the microstructures of the samples, which demonstrates that the proposed porosity equation is reliable and can be used in both mechanical analyses and coupled mechanical-electrochemical analyses for batteries.

\section{Acknowledgements}

The authors would like to thank Mr. Zhe Sun for the help of SEM characterisation.

\section{Appendix A.}

\section{A1. Details of thickness measuring}

In order to eliminate the measurement errors caused by the speckle patterns on the surface and the curling at the edges, a supplementary uniaxial tensile test was carried out for the thickness measurement. The sample size here was determined to be a $160 \mathrm{~mm} \times 25 \mathrm{~mm}$ strip and the starting grip separation was set as $100 \mathrm{~mm}$. All supplementary tests were conducted following the method described in Section 2.2, but they were stopped when the crosshead displacement reached $100 \mathrm{~mm}$. A digital micrometre with high precision of $1 \mu \mathrm{m}$ was used by following the TAPPI T411 method. The measurement was stopped by the top ratchet when the contact force reaches 5-10 $\mathrm{N}$ to ensure the accuracy of the measurement. All samples were measured before and after the tensile test and the measurements were repeated 5 times for each specimen. The measuring results are summarised in Table A1.

\section{Table A1}

The thickness values of separator samples.

\begin{tabular}{llll}
\hline Sample & Direction & \multicolumn{2}{l}{ Thickness $(\mu \mathrm{m})$} \\
& & Before test & After test \\
\hline Celgard 2325 & MD & $25 \pm 1$ & $25 \pm 1$ \\
& TD & & $18 \pm 1$ in the necking region and $25 \pm 1$ in other regions \\
Celgard 2500 & MD & $25 \pm 1$ & $25 \pm 1$ \\
& TD & & $25 \pm 1$
\end{tabular}


$\begin{array}{llll}\text { Hipore-16 } & \text { MD } & 16 \pm 1 & 16 \pm 1 \\ & \text { TD } & & 16 \pm 1\end{array}$

Hipore-25 MD $25 \pm 1 \quad 25 \pm 2$

TD $25 \pm 2$

\section{A2. Other supplementary experimental figures}

Fig. Al shows the uniaxial tensile engineering stress-strain curves with error bars (determined by standard deviation) for all samples.

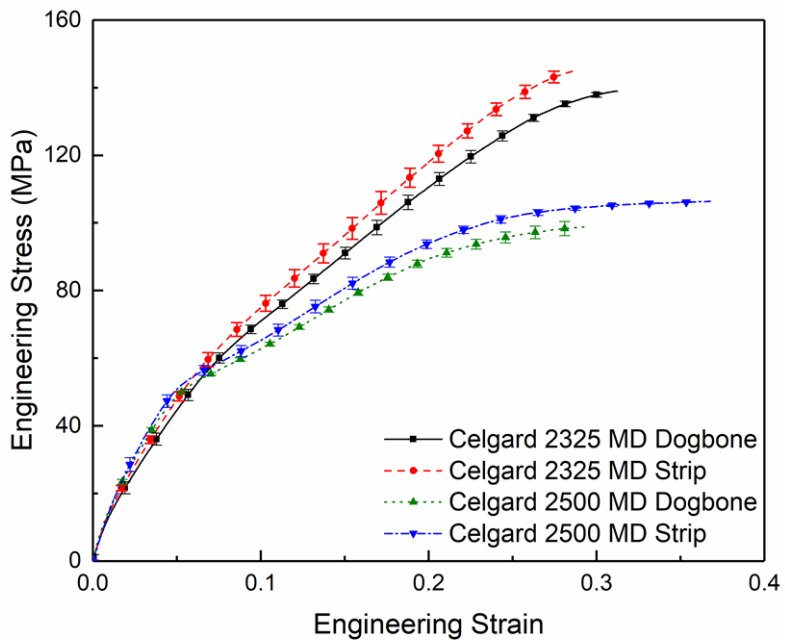

(a)

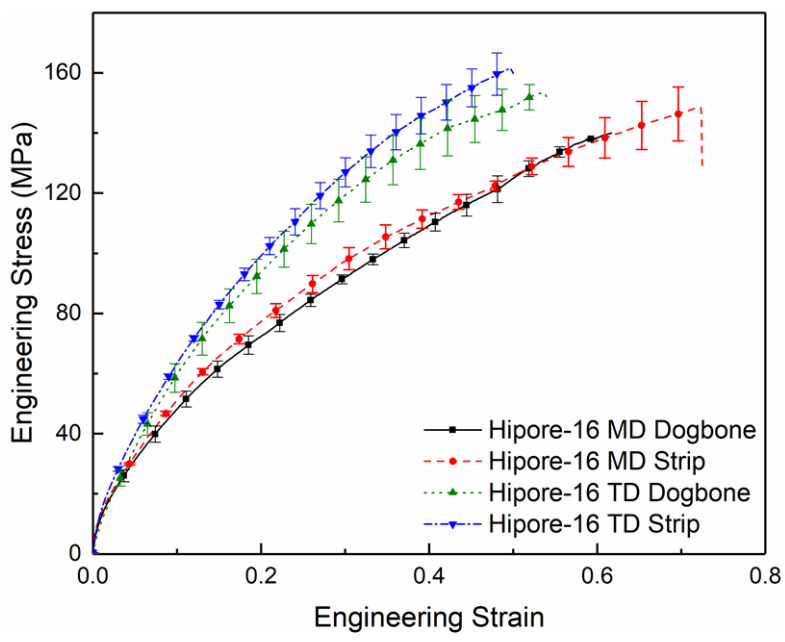

(c)

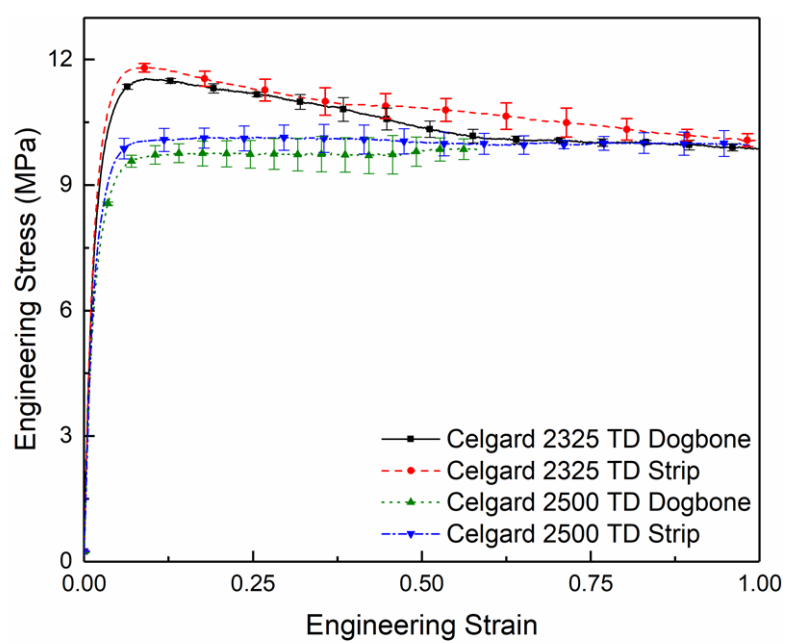

(b)

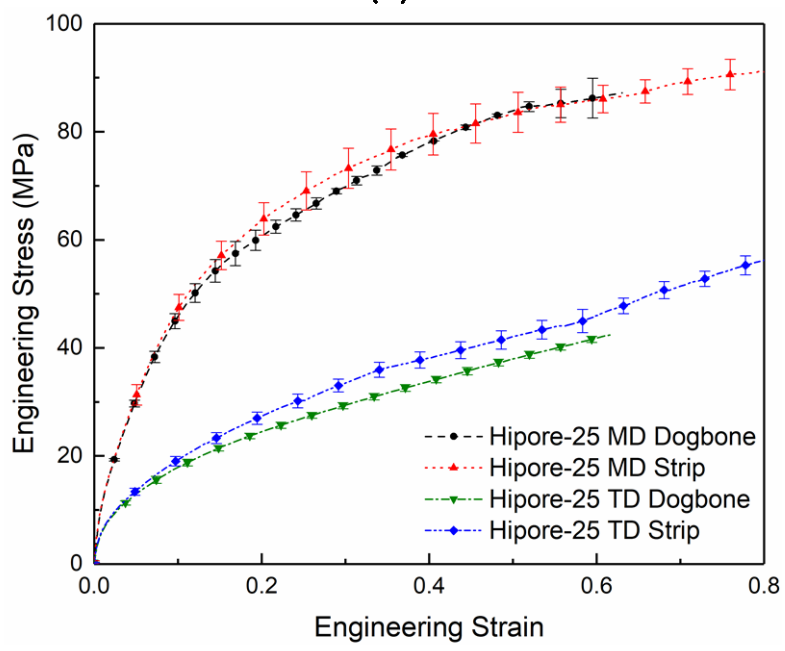

(d)

Fig. A1 Engineering stress-strain curves of (a) Celgard separators in MD, (b) Celgard separators in TD, (c) Hipore-16 and (d) Hipore-25.

Fig. A2 and A3 shows the homogeneous strain distributions for dry-processed Celgard separators in MD and wet-processed Hipore separators in both directions. 


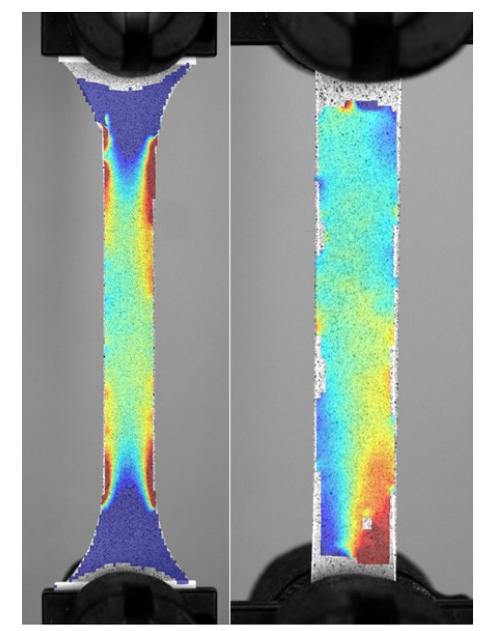

(a)

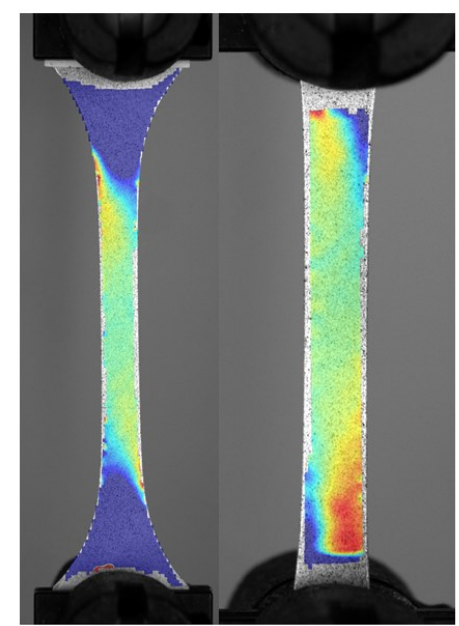

(b)

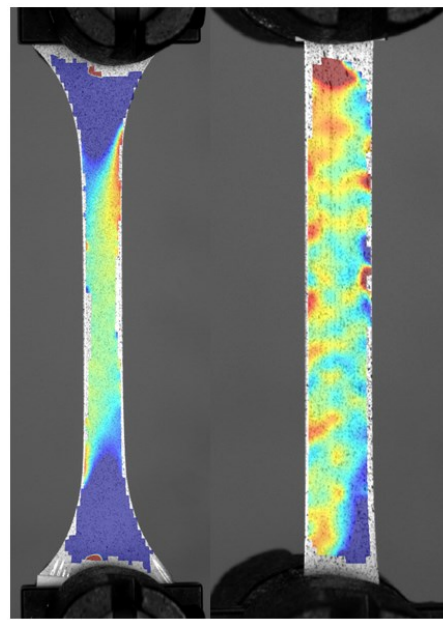

(c)

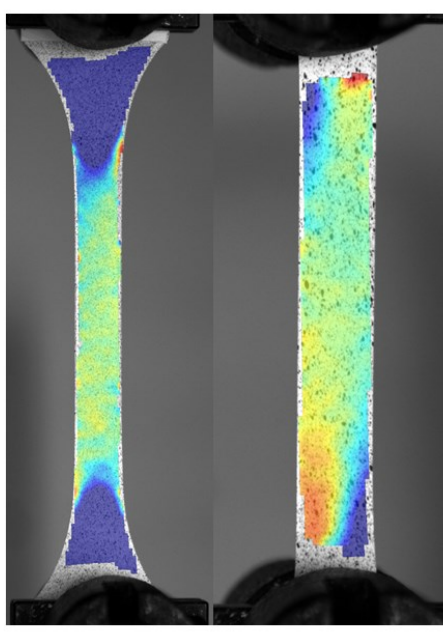

(d)

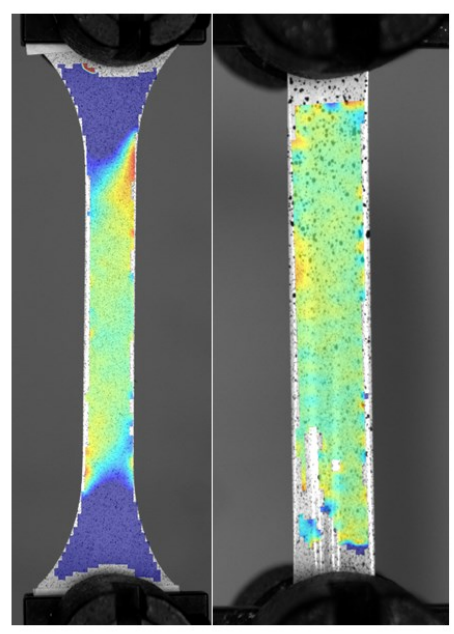

(e)
21.6

21.2

20.8

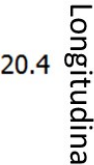

$20.0 \stackrel{\frac{2}{ \pm}}{\frac{2}{3}}$

$19.6 \stackrel{\sum}{\text { å }}$

19.2

18.8

18.4

18.0

Fig. A2 Full-field longitudinal strains of (a) Celgard 2500 MD, (b) Hipore-16 MD, (c) Hipore-16 TD, (d) Hipore-25 MD, and (e) Hipore-25 TD. 


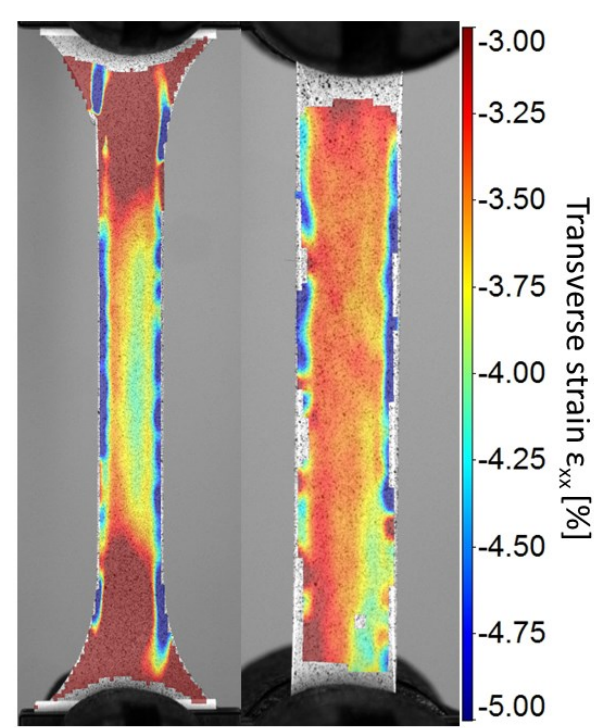

(a)

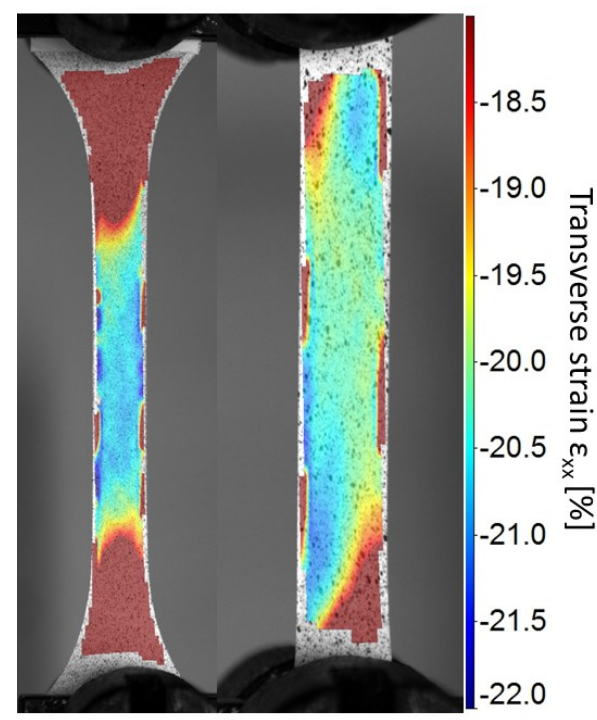

(c)

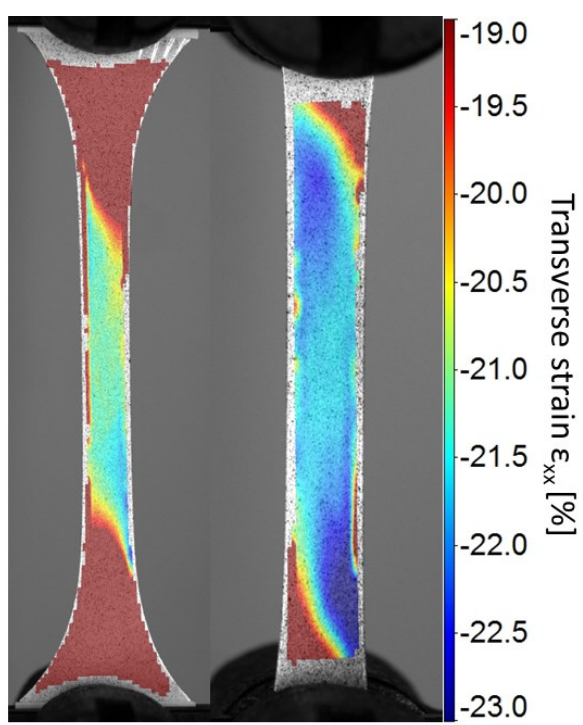

(b)

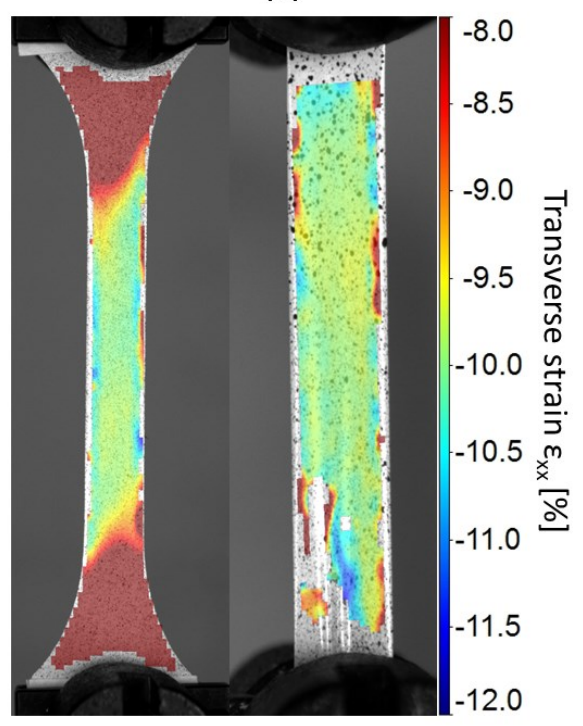

(d)

Fig. A3 Full-field transverse strains of (a) Celgard 2500 MD, (b) Hipore-16 MD, (c) Hipore$25 \mathrm{MD}$, and (d) Hipore-25 TD.

Fig. A4 shows the consistent transverse strain vs. longitudinal strain curves of samples without wrinkling and structure rupture. 

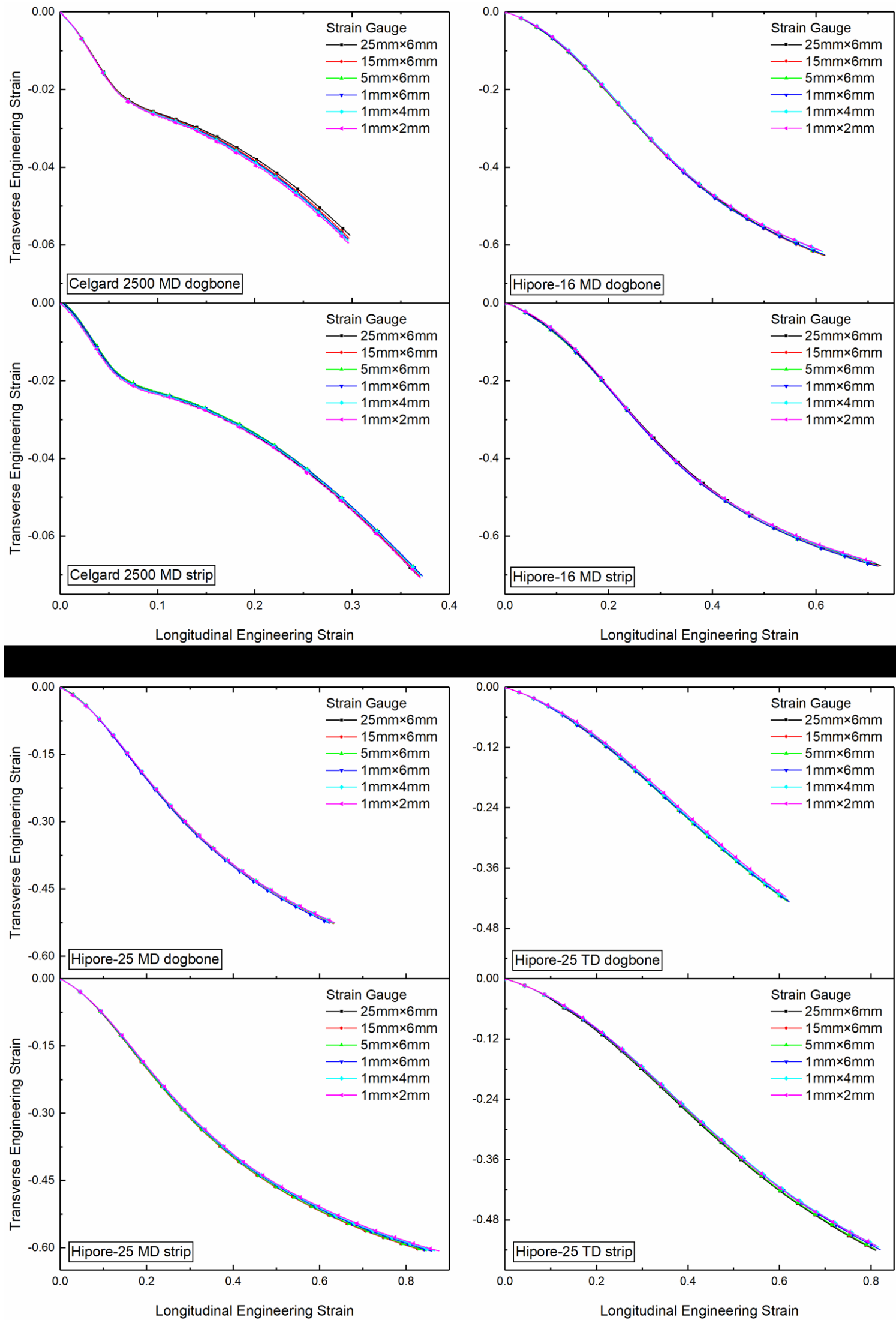

Longitudinal Engineering Strain

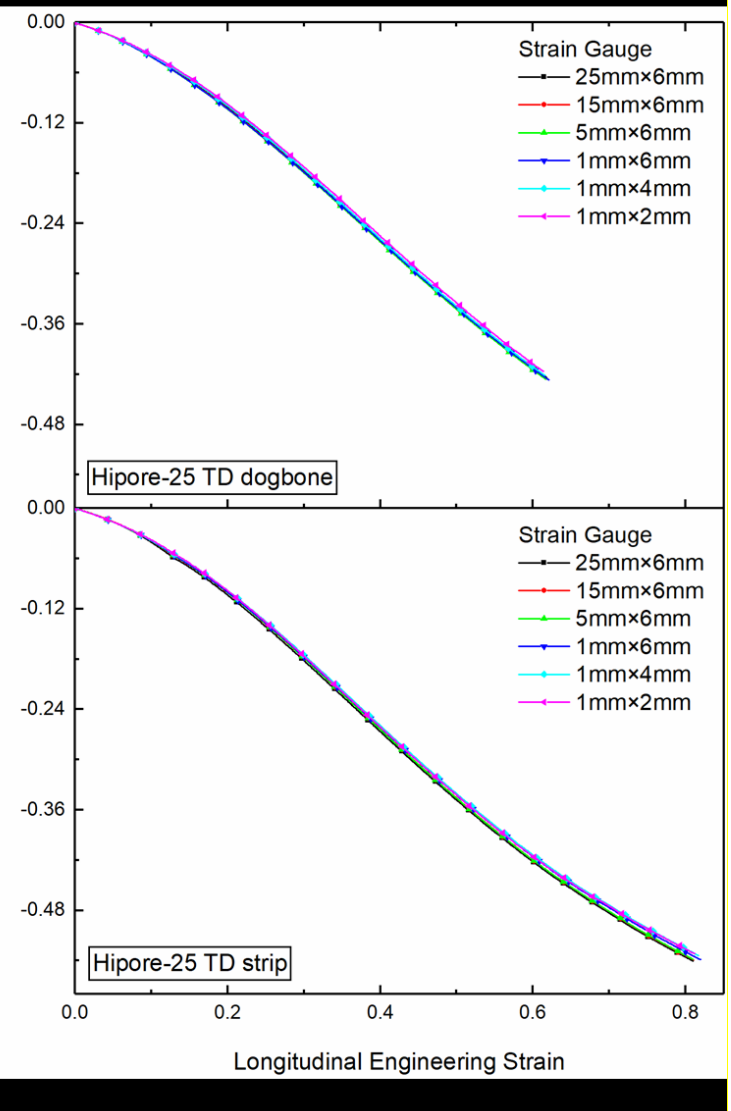

Fig. A4 The transverse strain vs. longitudinal strain curves with different VSG for (a) Celgard 2500 MD, (b) Hipore-16 MD, (c) Hipore-25 MD , and (d) Hipore-25 TD. 


\section{References}

[1] P. Arora, Z.J. Zhang, Battery separators, Chem. Rev., 104 (2004) 4419-4462.

[2] S.S. Zhang, A review on the separators of liquid electrolyte Li-ion batteries, J. Power Sources, 164 (2007) 351-364.

[3] C.J. Orendorff, The role of separators in lithium-ion cell safety, Electrochem. Soc. Interface, 21 (2012) 61-65.

[4] B. Liu, S. Yin, J. Xu, Integrated computation model of lithium-ion battery subject to nail penetration, Appl. Energy, 183 (2016) 278-289.

[5] J. Cannarella, X.Y. Liu, C.Z. Leng, P.D. Sinko, G.Y. Gor, C.B. Arnold, Mechanical properties of a battery separator under compression and tension, J. Electrochem. Soc., 161 (2014) F3117-F3122.

[6] W. Xie, W. Liu, Y. Dang, A. Tang, T. Deng, W. Qiu, Investigation on electrolyteimmersed properties of lithium-ion battery cellulose separator through multi-scale method, J. Power Sources, 417 (2019) 150-158.

[7] J. Xu, L. Wang, J. Guan, S. Yin, Coupled effect of strain rate and solvent on dynamic mechanical behaviors of separators in lithium ion batteries, Mater. Des, 95 (2016) 319-328.

[8] S. Kalnaus, Y. Wang, J. Li, A. Kumar, J.A. Turner, Temperature and strain rate dependent behavior of polymer separator for Li-ion batteries, Extreme Mech. Lett., 20 (2018) 73-80.

[9] X. Zhang, J. Zhu, E. Sahraei, Degradation of battery separators under charge-discharge cycles, RSC Adv., 7 (2017) 56099-56107.

[10] S. Kalnaus, Y. Wang, J.A. Turner, Mechanical behavior and failure mechanisms of Liion battery separators, J. Power Sources, 348 (2017) 255-263.

[11] E. Sahraei, M. Kahn, J. Meier, T. Wierzbicki, Modelling of cracks developed in lithiumion cells under mechanical loading, RSC Adv., 5 (2015) 80369-80380.

[12] C. Zhang, J. Xu, L. Cao, Z. Wu, S. Santhanagopalan, Constitutive behavior and progressive mechanical failure of electrodes in lithium-ion batteries, J. Power Sources, 357 (2017) 126-137.

[13] X. Zhang, E. Sahraei, K. Wang, Deformation and failure characteristics of four types of lithium-ion battery separators, J. Power Sources, 327 (2016) 693-701.

[14] X. Zhang, E. Sahraei, K. Wang, Li-ion battery separators, mechanical integrity and failure mechanisms leading to soft and hard internal shorts, Sci Rep, 6 (2016) 32578.

[15] S. Kalnaus, A. Kumar, Y. Wang, J. Li, S. Simunovic, J.A. Turner, P. Gorney, Strain distribution and failure mode of polymer separators for Li-ion batteries under biaxial loading, J. Power Sources, 378 (2018) 139-145.

[16] H. Luo, X. Jiang, Y. Xia, Q. Zhou, Fracture mode analysis of lithium-ion battery under mechanical loading, in: International Mechanical Engineering Congress and Exposition, ASME, Houston, Texas, USA, 2015, pp. V009T012A052-V009T012A052.

[17] N. McCormick, J. Lord, Digital Image Correlation, Mater. Today, 13 (2010) 52-54.

[18] S. Yan, J. Deng, C. Bae, Y. He, A. Asta, X.R. Xiao, In-plane orthotropic property characterization of a polymeric battery separator, Polym. Test., 72 (2018) 46-54.

[19] P. Lava, S. Coppieters, Y. Wang, P. Van Houtte, D. Debruyne, Error estimation in measuring strain fields with DIC on planar sheet metal specimens with a non-perpendicular camera alignment, Opt. Lasers Eng., 49 (2011) 57-65.

[20] M.A. Sutton, J.H. Yan, V. Tiwari, H.W. Schreier, J.J. Orteu, The effect of out-of-plane motion on 2D and 3D digital image correlation measurements, Opt. Lasers Eng., 46 (2008) 746-757.

[21] A. Elmahdy, P. Verleysen, The use of 2D and 3D high-speed digital image correlation in full field strain measurements of composite materials subjected to high strain rates, in: ICEM 2018, Brussels, Belgium 2018, pp. 538. 
[22] J. Zhu, X. Zhang, T. Wierzbicki, Stretch-induced wrinkling of highly orthotropic thin films, Int. J. Solids Struct., 139 (2018) 238-249.

[23] V. Nayyar, K. Ravi-Chandar, R. Huang, Stretch-induced wrinkling of polyethylene thin sheets: Experiments and modeling, Int. J. Solids Struct., 51 (2014) 1847-1858.

[24] D.H. Shi, X.R. Xiao, X.S. Huang, H. Kia, Modeling stresses in the separator of a pouch lithium-ion cell, J. Power Sources, 196 (2011) 8129-8139.

[25] J. Nunes-Pereira, C.M. Costa, R. Leones, M.M. Silva, S. Lanceros-Méndez, Li-ion battery separator membranes based on poly(vinylidene fluoride-trifluoroethylene)/carbon nanotube composites, Solid State Ionics, 249-250 (2013) 63-71.

[26] H. Lee, M. Yanilmaz, O. Toprakci, K. Fu, X.W. Zhang, A review of recent developments in membrane separators for rechargeable lithium-ion batteries, Energy Environ. Sci., 7 (2014) 3857-3886.

[27] J. Cannarella, C.B. Arnold, The effects of defects on localized plating in lithium-ion batteries, J. Electrochem. Soc., 162 (2015) A1365-A1373.

[28] Y. Zhao, F.B. Spingler, Y. Patel, G.J. Offer, A. Jossen, Localized swelling inhomogeneity detection in lithium ion cells using multi-dimensional laser scanning, J. Electrochem. Soc., 166 (2019) A27-A34.

[29] V. Deimede, C. Elmasides, Separators for lithium-ion batteries: A review on the production processes and recent developments, Energy Technol., 3 (2015) 453-468.

[30] L. Greve, C. Fehrenbach, Mechanical testing and macro-mechanical finite element simulation of the deformation, fracture, and short circuit initiation of cylindrical Lithium ion battery cells, J. Power Sources, 214 (2012) 377-385.

[31] E. Sahraei, J. Campbell, T. Wierzbicki, Modeling and short circuit detection of 18650 Li-ion cells under mechanical abuse conditions, J. Power Sources, 220 (2012) 360-372.

[32] J. Xu, B. Liu, L. Wang, S. Shang, Dynamic mechanical integrity of cylindrical lithiumion battery cell upon crushing, Eng. Fail. Anal., 53 (2015) 97-110.

[33] L. Wang, S. Yin, J. Xu, A detailed computational model for cylindrical lithium-ion batteries under mechanical loading: From cell deformation to short-circuit onset, J. Power Sources, 413 (2019) 284-292.

[34] M.F. Lagadec, R. Zahn, V. Wood, Designing polyolefin separators to minimize the impact of local compressive stresses on lithium ion battery performance, J. Electrochem. Soc., 165 (2018) A1829-A1836.

[35] J. Cannarella, C.B. Arnold, Ion transport restriction in mechanically strained separator membranes, J. Power Sources, 226 (2013) 149-155.

[36] B. Liu, Y. Jia, C. Yuan, L. Wang, X. Gao, S. Yin, J. Xu, Safety issues and mechanisms of lithium-ion battery cell upon mechanical abusive loading: A review, Energy Storage Materials, 24 (2020) 85-112.

[37] V. Nayyar, K. Ravi-Chandar, R. Huang, Stretch-induced stress patterns and wrinkles in hyperelastic thin sheets, Int. J. Solids Struct., 48 (2011) 3471-3483.

[38] J. Zhu, X. Zhang, H. Luo, E. Sahraei, Investigation of the deformation mechanisms of lithium-ion battery components using in-situ micro tests, Appl. Energy, 224 (2018) 251-266.

[39] Y. Yu, B. Xiong, F.X. Zeng, R. Xu, F. Yang, J. Kang, M. Xiang, L. Li, X. Sheng, Z. Hao, Influences of compression on the mechanical behavior and electrochemical performances of separators for lithium ion batteries, Ind. Eng. Chem. Res., 57 (2018) 1714217151.

[40] L. Palacio, P. Pradanos, J.I. Calvo, A. Hernandez, Porosity measurements by a gas penetration method and other techniques applied to membrane characterization, Thin Solid Films, 348 (1999) 22-29.

[41] L.M. Anovitz, D.R. Cole, Characterization and analysis of porosity and pore structures, Rev. Mineral. Geochem., 80 (2015) 61-164. 
[42] D.P. Finegan, S.J. Cooper, B. Tjaden, O.O. Taiwo, J. Gelb, G. Hinds, D.J.L. Brett, P.R. Shearing, Characterising the structural properties of polymer separators for lithium-ion batteries in 3D using phase contrast X-ray microscopy, J. Power Sources, 333 (2016) 184-192. [43] C.A. Peabody, Characterization of Mechanical Stress Effects on Lithium-ion Battery Materials, Princeton University, 2011.

[44] J.E. Mark, Polymer Data Handbook (2nd Edition), Oxford University Press, 2009.

[45] E. Cerda, K. Ravi-Chandar, L. Mahadevan, Wrinkling of an elastic sheet under tension, Nature, 419 (2002) 579. 